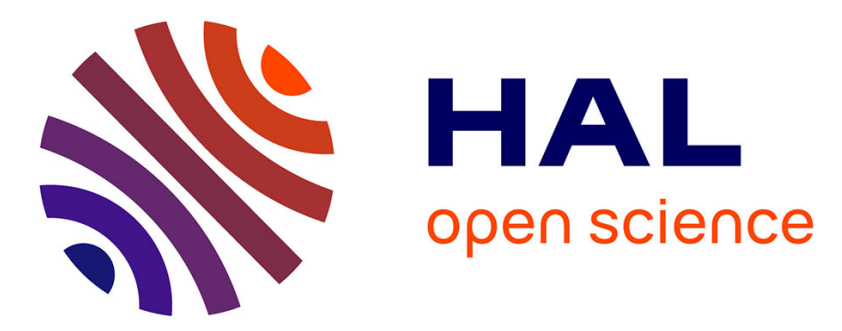

\title{
Reflooding with internal boiling of a heating model porous medium with mm-scale pores
}

\author{
Paul Sapin, Ange Gourbil, Paul Duru, Florian Fichot, Marc Prat, Michel
}

Quintard

\section{To cite this version:}

Paul Sapin, Ange Gourbil, Paul Duru, Florian Fichot, Marc Prat, et al.. Reflooding with internal boiling of a heating model porous medium with mm-scale pores. International Journal of Heat and Mass Transfer, 2016, vol. 99, pp. 512-520. 10.1016/j.ijheatmasstransfer.2016.04.013 . hal-01347198

\section{HAL Id: hal-01347198 \\ https://hal.science/hal-01347198}

Submitted on 20 Jul 2016

HAL is a multi-disciplinary open access archive for the deposit and dissemination of scientific research documents, whether they are published or not. The documents may come from teaching and research institutions in France or abroad, or from public or private research centers.
L'archive ouverte pluridisciplinaire HAL, est destinée au dépôt et à la diffusion de documents scientifiques de niveau recherche, publiés ou non, émanant des établissements d'enseignement et de recherche français ou étrangers, des laboratoires publics ou privés. 


\section{Open Archive TOULOUSE Archive Ouverte (OATAO)}

OATAO is an open access repository that collects the work of Toulouse researchers and makes it freely available over the web where possible.

This is an author-deposited version published in: http://oatao.univ-toulouse.fr/ Eprints ID : 15884

To link to this article : DOI:10.1016/j.ijheatmasstransfer.2016.04.013

URL : http://dx.doi.org/10.1016/j.ijheatmasstransfer.2016.04.013

\section{To cite this version :}

Sapin, Paul and Gourbil, Ange and Duru, Paul and Fichot, Florian and Prat, Marc and Quintard, Michel Reflooding with internal boiling of a heating model porous medium with mm-scale pores. (2016) International Journal of Heat and Mass Transfer, vol. 99. pp. 512-520. ISSN 0017-9310

Any correspondence concerning this service should be sent to the repository administrator: staff-oatao@ listes-diff.inp-toulouse.fr 


\title{
Reflooding with internal boiling of a heating model porous medium with mm-scale pores
}

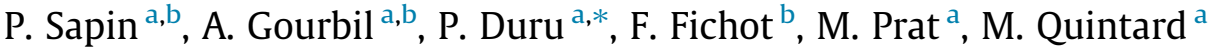 \\ a Institut de Mécanique des Fluides de Toulouse (IMFT) - Université de Toulouse, CNRS-INPT-UPS, Toulouse, France \\ ${ }^{\mathrm{b}}$ Institut de Radioprotection et de Sûreté Nucléaire (IRSN), Division of Major Accidents Prevention, BP3 13115 St Paul lez Durance, France
}

Keywords:

Nuclear safety

Hot debris bed

Boiling

Porous media

\begin{abstract}
A B S T R A C T
This paper presents a pore-scale experimental study of the reflooding of a two-dimensional model porous medium. The objective is to better understand the reflooding mechanisms in play in the context of nuclear reactor safety. The hot debris bed that forms in a nuclear reactor following a loss of coolant accident is comparable to a heat-generating porous medium. Its cooling by water reflooding involves intense boiling mechanisms that must be modeled properly to assess mitigation procedures.

The experimental study presented in this paper focuses on the phenomenology of reflooding of a model porous medium composed of a bank of mm-scale heating cylinders placed between two ceramic plates. A Fluorinert ${ }^{\mathrm{TM}}$ liquid, HFE-7000, is injected at a temperature close to saturation into the dry and superheated porous medium. Each cylinder of the test section is used both as a heating element and a temperature probe, which enables to track the evolution of the three different macroscopic zones identified during cooling of the system. The reflooding dynamics, in particular the cooling fronts velocities, are thus determined thanks to pore-scale thermal measurements together with direct visualizations. The influence of the injection flow rate and of the heating power are studied in a parametric way.
\end{abstract}

\section{Introduction}

In the aftermath of a loss of coolant accident (LOCA scenario), residual decay heat in a nuclear reactor core can cause dry-out of water in the vessel, destruction of fuel rods and melting of core materials, thus creating a molten pool commonly called corium. To prevent the spread of molten materials, the reactor vessel can be cooled down by reflooding with water. Yet, quenching of very hot rods in the upper plenum may result in their collapse, thus forming a debris bed heated up by residual decay heat, comparable to a highly permeable porous medium: the typical particle size, $d_{\mathrm{p}}$, is in the range $1-10 \mathrm{~mm}$, which is of the same order of magnitude as the water capillary length. Reflooding of this dry and heatgenerating porous medium is a crucial step in the cooling process. Indeed, a non-coolable particle bed might melt down, thus expanding the corium pool and possibly damaging the reactor vessel.

In terms of nuclear safety analysis, intense boiling mechanisms and complex flow regimes encountered at the pore scale in the debris bed must be modeled properly to estimate the efficiency of the reflooding and to assess mitigation procedures in case of such severe accident. Many experimental studies have been undertaken in the past decades for understanding boiling in porous media under various conditions: pool boiling [1-5], coolant entry from the top [6-9] or bottom [6,10-15] to cite a few. Of particular interest in such experiments is the determination of dryout or reflooding conditions and model validation. A classical modeling approach consists in describing this complex three-phase system (two-phase cross-flow with liquid-vapor phase change within a heated packed particle bed) at a macroscopic scale by writing macro-scale conservation equations for an equivalent continuous media, whose properties at each point are effective transport properties representative of the pore-scale configuration. Given the thermal constraints observed in debris bed cooling problems, several major modeling issues must be addressed. What is the structure of macro-scale momentum equation and energy balance? May the models be determined in an uncoupled manner, i.e., is it possible to determine two-phase flow equations and effective properties independently from the pore-scale boiling mechanisms? Most models make use of such an assumption. Twophase flow equations are based on generalized Darcy's laws [16], Ergun's extensions taking into account inertia effects $[17,4,9]$, equations with interfacial drag terms $[18,19]$. Interestingly, the model in [19] introduces the idea of different pore-scale organization of the phases depending on the flow rates and saturation, 


\author{
Nomenclature \\ $d_{\mathrm{c}} \quad$ cylinder diameter (RTD probe diameter), $\mathrm{m}$ \\ $d_{\mathrm{p}} \quad$ diameter of the particles formed by the collapse of fuel \\ rods, $m$ \\ $\varepsilon \quad$ porosity, - \\ $G_{l} \quad$ flow rate, $\mathrm{m}^{3} / \mathrm{s}$ \\ $L_{\mathrm{htl}} \quad$ vertical extent of the heat transfer layer, $\mathrm{m}$ \\ $Q \quad$ heating power per cylinder, W \\ $S \quad$ setup cross-section area, $\mathrm{m}^{2}$ \\ $t_{c} \quad$ time when a cylinder is said to be reflooded or cooled \\ down, s \\ $t_{\mathrm{qf}} \quad$ time of arrival of the quenching front, $\mathrm{s}$

inlet temperature, ${ }^{\circ} \mathrm{C}$

saturation temperature, ${ }^{\circ} \mathrm{C}$

intrinsic liquid velocity, $\mathrm{m} / \mathrm{s}$

velocity of the quenching front, $\mathrm{m} / \mathrm{s}$

velocity of the cooling front, $\mathrm{m} / \mathrm{s}$

position of the quenching front in the $y$-direction deduced from thermal measurements, $m$ position of the quenching front in the $y$-direction, $\mathrm{m}$ position of the cooling front in the $y$-direction deduced from thermal measurements, $\mathrm{m}$ repartition possibly dependent upon the pore-scale boiling mechanisms. However, all these models rely up to a certain point on some heuristic views of the pore-scale physics, as well as on some heuristic upscaling rules that deserve further investigations. The heat transfer macro-scale equations in most models are based on a macro-scale energy balance written assuming thermal equilibrium $[16,20]$, while based on some experimental evidence, nonequilibrium models were also proposed $[21,22,14]$.

Indeed, thermal inertia of the particles, important convective heat transfers and rapid evaporation processes are responsible for significant local differences between the three phaseaveraged temperatures defined for the solid, liquid and gas phases. Such a local thermal non-equilibrium situation requires the introduction of separate energy equations for the different phases. Duval et al. [23] derived macroscopic equations from the local energy and mass conservation laws with the volume averaging method [24]. They obtained macroscopic laws for the gas, liquid and solid phases, accounting for diffusion, convection and evaporation contributions. Providing explicit relations between the effective properties of the macroscopic model and the pore-scale configuration requires to write local closure problems to be solved over representative unit cells.

So far, the theoretical results involve several assumptions that are not necessarily compatible with the various pore-scale flow mechanisms. The major assumptions which require further investigations are listed below:

- Pore-scale two-phase flow configurations are assumed to be known a priori in the heat transfer upscaling problem. Furthermore, the interface is assumed to obey a quasi-static assumption [25].

- The time-scales are separated enough so that the time convolutions that arise in the upscaling process can be discarded $[26,27]$. The resulting model is a three-temperature model.

Obviously, these assumptions do not seem compatible with intense boiling, characterized by rapid movements of the phases and interfaces. Finally, because of the lack of pore-scale knowledge of the various configurations, the effective properties have been determined analytically for very simple unit cells, considering two main configurations: stratified solid-liquid-gas (SLG, where liquid is the wetting phase) or solid-gas-liquid (SGL, where gas is the wetting phase) flows, this latter configuration being reminiscent of a film boiling situation. These simple calculations emphasized the strong impact of the phases repartition upon the effective properties.

Practical application of these developments to convective boiling problems in porous media faces a major difficulty. Boiling phenomena lead to various, often highly transient, liquid-gas repartitions, especially at the solid-fluids interface where both liq- uid and gas can wet the solid surface. Heterogeneous nucleation and coalescence of bubbles are indeed complex processes that can hardly be described by stratified configurations with static interfaces, such as SLG or SGL configurations. While the above analysis suggests that the complete up-scaling problem, i.e., the coupled mass, momentum and energy balance equations, should be reviewed, we focus in this paper on the heat exchange between the different phases.

Comprehensive approaches have already been proposed to predict heat exchanges in boiling configurations and successfully compared to experimental data obtained on micro-fabricated surfaces. For instance, studies by Liter and Kaviany [28] and Dhir [29,30] allow to be optimistic that comprehensive models should be able to estimate boiling heat transfer in complex configurations. However, to our knowledge, no correlation is currently available to estimate the convective boiling contribution to heat exchanges during reflooding of a porous medium. Bachrata et al. [14] thus proposed a semi-heuristic approach that consists of adding heat source terms into the solid energy equation of Duval et al.'s model [23] to account for nucleate, transition and film boiling contributions, with empirical or mechanism-based correlations. The key challenge is to select adapted correlations, because of the numerous influential parameters. In particular, Kew and Cornwell [31], Thome [32] and Cheng and $\mathrm{Wu}$ [33] outlined the strong effect of confinement on boiling phenomenology and on the resulting heat transfer coefficient. Also, with any of the transition criteria proposed in these studies, the different characteristic flow paths in the concerned packed debris beds can be classified as either macroscale, mesoscale and microscale channels with respect to two-phase processes (considering vapor and liquid water).

It is thus essential to obtain pore-scale visualization about phase distribution that will help either:

- to estimate effective transport properties in more realistic representative unit cells, and/or

- to choose more carefully convective boiling correlations for heuristic or semi-heuristic approaches.

Such information was not obtained in previous experimental studies of reflooding of superheated porous structures, a subject investigated experimentally since the 1980s [34,35,10,36]. In fact, such studies are typically performed on 3D packing of superheated beads, preventing any visualization at pore scale. They aim primarily at obtaining data at macroscopic scale (pressure, global vapor production,...) that can be used to adjust parameters of some macroscopic models (see, e.g., the insights obtained from Repetto et al. [37], Bachrata et al. [14] and Fichot et al.'s [38] experimental studies on Duval et al.'s modeling [23]).

The present experimental work aims at obtaining direct visualizations of the reflooding of a model porous medium, together with 
thermal measurements at pore scale. The experimental setup and techniques are first described in Section 2. The salient features of the reflooding in such a system are then presented. First, in Section 3.1, a description of the transient two-phase flow taking place in the porous medium during the reflooding is given. The heat transfer mechanisms between the heated solid matrix and the reflooding fluid are identified. Then, we turn to quantitative measurement of the propagation of the quenching and cooling front observed during reflooding, as a function of the heated matrix temperature and fluid injection velocity (Sections 3.2 and 3.3). Conclusions and perspectives for further work are then drawn in Section 4

\section{Experimental setup and measurement techniques}

\subsection{Experimental setup}

The experimental test section consists of a nearly twodimensional porous medium made of 392 cylinders placed between two parallel ceramic plates and held vertically, see Fig. 1. The spacing between the two plates is $3 \mathrm{~mm}$. The $2.1 \mathrm{~mm}$ diameter cylinders are positioned in a slightly randomlydisturbed staggered arrangement that spans the setup width $(50 \mathrm{~mm}$ ) and extends over a $80 \mathrm{~mm}$ height. The resulting porosity is then $\varepsilon=0.65$. The two plates are respectively a Macor $^{\mathrm{TM}}$ ceramic plate and a polished, transparent Vycor ${ }^{\circledR}$ glass plate which seals the test section while allowing visualization. These materials have been chosen because of their ability to withstand high temperatures. The porous section is preceded by a divergent part to obtain a flat liquid injection front. The two-phase mixture exits at the top of the test section.

The key feature of the experimental test section lies in the fact that each cylinder is a Pt-100 resistance temperature detector (RTD) composed of a coiled platinum wire wrapped around an insulating core, sealed into a $2.1 \mathrm{~mm}$ diameter and $7 \mathrm{~mm}$ long ceramic coating (see Fig. 1). Each RTD is used as a heating element

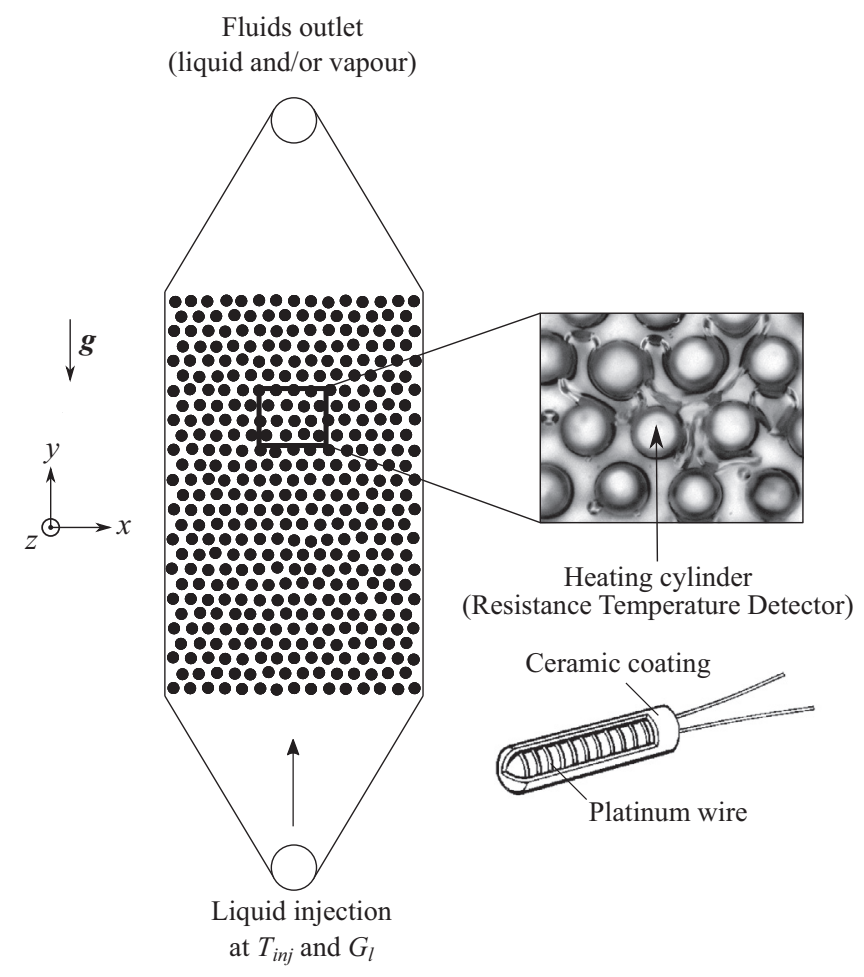

Fig. 1. Sketch of the experimental test section: a "two-dimensional" model porous medium. Each cylinder is a platinum resistance temperature detector. but also as a local temperature probe, as explained in Section 2.2.1. Note that the smaller size of the heating cylinders and their strong confinement between the two ceramic plates are two major differences with typical tube bundle geometries, for which convective boiling has been studied experimentally since the early 1950s (see, e.g., [39-41]).

HFE-7000 was chosen as the working fluid because of its low saturation temperature $\left(T_{\text {sat }}=34{ }^{\circ} \mathrm{C}\right.$ at atmospheric pressure). Reflooding experiments can then be run with moderate thermal constraints. In addition, this Fluorinert ${ }^{\mathrm{TM}}$ fluid is non-toxic, nonflammable and dielectric, which guarantees safety during handling. HFE-7000 perfectly wets the ceramic surfaces it is in contact with (contact angle close to $0^{\circ}$ ). Also, it is worth mentioning that the ratio of the capillary length of HFE-7000 to the diameter of the cylindrical heating elements is similar to the one obtained when considering the ratio between the capillary length of water at $100{ }^{\circ} \mathrm{C}$ and a characteristic $5 \mathrm{~mm}$ particle size, typical of the one observed in debris bed. Indeed, observations of the damaged TMI-2 reactor [42] and different experimental studies (see, e.g., the TMI-2 core sample examinations by McCardell et al. [43], the LOFT experiment analysis by Coryell et al. [44], and the microscopic observations of fuel samples made by Manzel and Walker [45]) characterized the particles formed by the collapse of fuel rods: their size $d_{\mathrm{p}}$ approximately lies between 1 and $10 \mathrm{~mm}$. Thus, realistic boiling conditions are obtained in the present experimental setup, as far as bubble size and confinement effects are concerned.

The fluid flow is driven by a gear pump (see Fig. 2(a)), the head of which is composed of stainless steel with PTFE teeth. The pump thus requires no lubrication and this cancels the risk of HFE-7000 contamination by a lubricating fluid. The fluid temperature is controlled by circulation through a coil immersed in a constant temperature bath. Inlet temperature $T_{\text {inj }}$ and flow rate $G_{1}$ are measured upstream of the test section. For the experiments reported in the present paper, the fluid was injected at a temperature close to its saturation temperature $\left(T_{\mathrm{inj}} \approx T_{\mathrm{sat}}\right)$. The intrinsic injection velocity $v_{1}$ is obtained by dividing the imposed flow rate by the product of the setup cross-section $S\left(3 \times 50 \mathrm{~mm}^{2}\right)$ times the porosity $\varepsilon$ :

$v_{1}=\frac{G_{1}}{\varepsilon S}$

In the present study, using $v_{1}$ rather than the flow rate $G_{l}$ is more relevant as $v_{1}$ is the theoretical average rising velocity of the liquid front in the test section, in the absence of phase change.

\subsection{Experimental techniques}

\subsubsection{Thermal control, temperature measurements and direct visualizations}

The electrical resistance of each RTD $\left(100 \Omega\right.$ at $\left.0{ }^{\circ} \mathrm{C}\right)$ varies with temperature according to a well-known law. RTDs are classically used with very low currents to measure resistance, and thus temperature, while avoiding self-heating. Whereas Joule effect is usually considered as a source of error, RTDs are used here both as heating elements and as local temperature probes. However, the dependence of resistance upon temperature leads to an additional challenge. In order to control the heating power transmitted to each cylinder, the voltage applied at the ends of each resistant wire must be adjusted continuously. All heating cylinders are connected to a stabilized power supply through a control module comprising a proportional-integral controller equipped with a $1000 \mathrm{~Hz}$ microprocessor. Each RTD therefore dissipates a well-controlled heat flux while its temperature is recorded at a very high acquisition rate. 


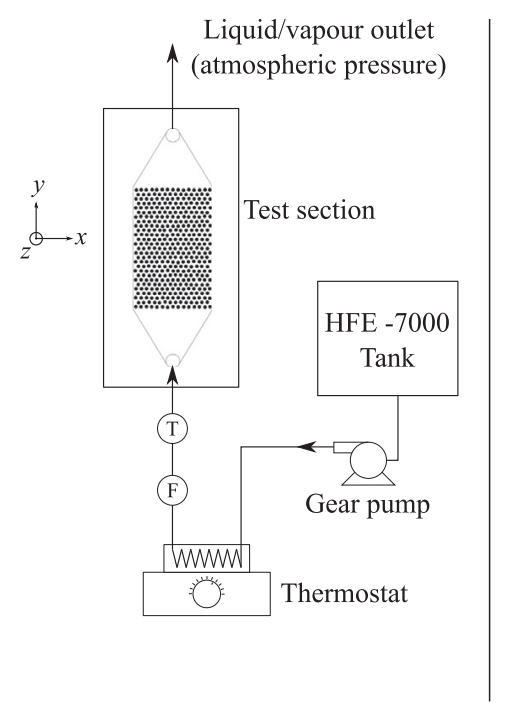

(a)

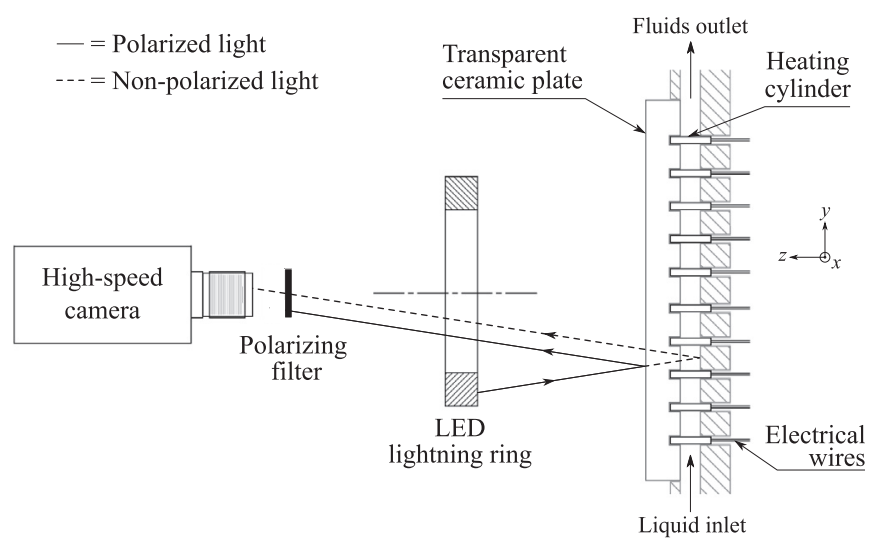

(b)

Fig. 2. (a) Experimental setup: an open fluid circuit. (b) Side view of the test section, showing the visualization configuration.

Insights on the liquid and vapor phases distribution during a reflooding experiment are obtained by direct visualization performed using a PCO Dimax high-speed camera. The frame acquisition rate is typically around 250 frames per second, with a low exposure time (1 ms) to avoid motion blur. A white LEDs ring providing a polarized light is placed in front of the transparent ceramic plate and aligned with the CCD (charge-coupled device) camera optical axis, see Fig. 2(b). This optical configuration limits the shadowing effect due to the many close cylinders that would have been obtained with a lighting from the side. Also, the amount of light that is simply reflected at the surface of the transparent ceramic plate is removed by a polarizing filter. This layout enables to achieve a nearly homogeneous lighting of the test section.

\subsubsection{Protocol for a reflooding experiment}

Reflooding experiments are performed on an uniformly heated model porous medium. The constant heating power applied to each cylinder, $Q$, and the liquid injection velocity, $v_{1}$, are the two experimental control parameters. The protocol for a reflooding experiment is the following.

First, the HFE-7000 tank is closed and a vacuum pump is connected at the top of the dry test section, to extract air from the whole fluid circuit. HFE-7000 tank is then opened so that the full system fills gently with liquid. This procedure aims at limiting the amount of air remaining trapped in the system. Second, a heating power is applied to the cylinders to dry the model porous medium while the test section top is opened at atmospheric pressure to avoid any pressure build-up. Finally, liquid is injected with a velocity $v_{1}$ in the dry porous medium saturated with HFE-7000 vapor and heated with a constant thermal power.

It is important to note that only a fraction of the bundle of cylinders is heated during a reflooding experiment, typically 14 rows of cylinders (203 cylinders) in the middle of the test section, see Fig. 3 (a). While limiting the total electric power to be delivered to the electronic control units, this is enough as measurements are then performed in a region of the system where the influence of entry and exit effects can be neglected (that is, respectively, establishment of the flow field in the porous bed, and flow recirculation in the top converging part of the test section, the influence of which extends over the very last rows of the test section).

A typical initial steady-state temperature profile is shown in Fig. 3(b) for a heating power $Q=80 \mathrm{~mW}$ per element. The observed thermal gradients are due to heat losses towards the side plates (ceramic) around the cylinder bundle, to heat conduction in those plates and to natural convection with air outside of the test section.

\section{Experimental results}

\subsection{Two-phase flow configuration and temperature distribution}

We first describe qualitatively the two-phase flow configuration typically observed in a reflooding experiment. Fig. 4 shows an image taken once the liquid has reached the heated porous region. In various experiments of quenching of superheated debris beds with bottom injection of a liquid coolant [6,10-15], three distinct regions were detected from temperature measurements at different locations within the bed. The present experiment provides the first direct observation of these zones, that are from top to bottom:

- a superheated vapor-dominated zone with some isolated liquid droplets ejected from the so-called heat transfer layer;

- a heat transfer layer (as designated by Tutu et al. [10]), that is an intense boiling zone where coalescence of bubbles is very frequent so that one can hardly discern any flow pattern;

- a reflooded - or quenched - region where heating cylinders are cooled down to near-saturation temperature, so that nucleate boiling takes place (isolated vapor bubbles can be clearly visualized).

A fourth zone corresponding to a one-phase liquid flow could be observed in such experiments if the subcooling of the fluid was higher. This condition was not fulfilled for this experiment because the liquid enters almost at saturation temperature. Two important findings from these observations are the presence of isolated liquid droplets in the vapor-dominated zone and the formation of vapor slugs in the heat transfer layer. The ejection of liquid drops at the quenching front, also called sputtering, favors precursory cooling of the superheated solid elements ahead of the quenching front. This phenomenon is not accounted for in the models presented in the Introduction of this paper. The formation of vapor slugs in the heat transfer layer is reminiscent of boiling in microchannels, for which the boiling phenomenology is different in comparison with macrochannels. 


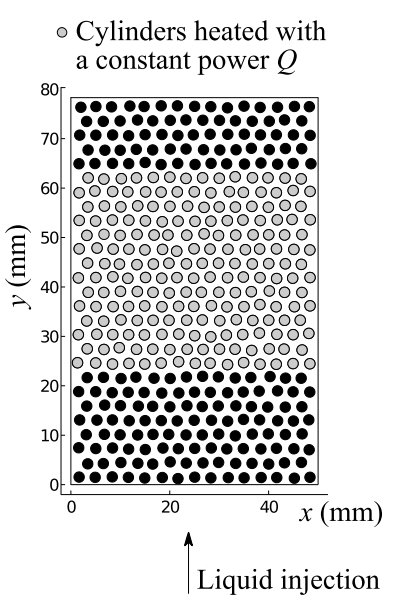

(a)

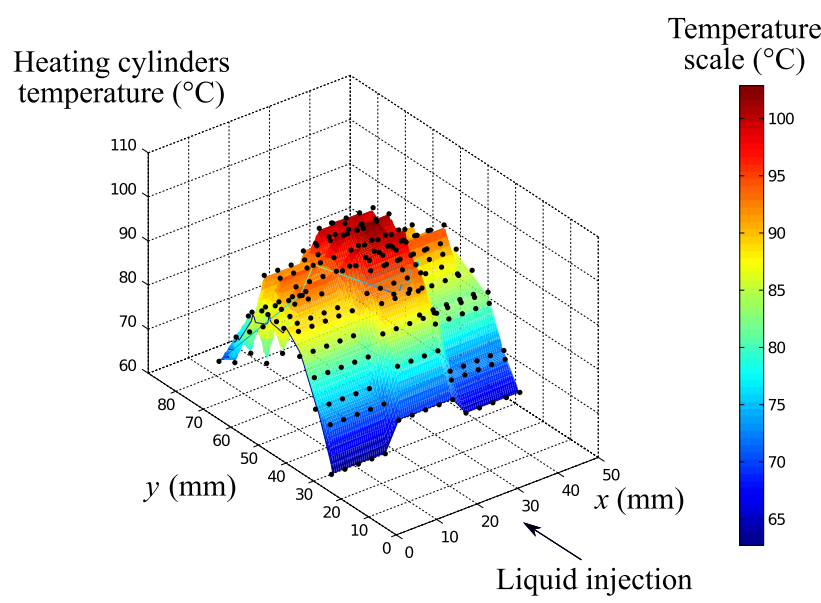

(b)

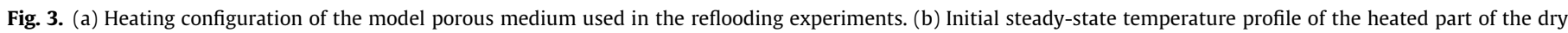
porous medium $(Q=80 \mathrm{~mW})$.

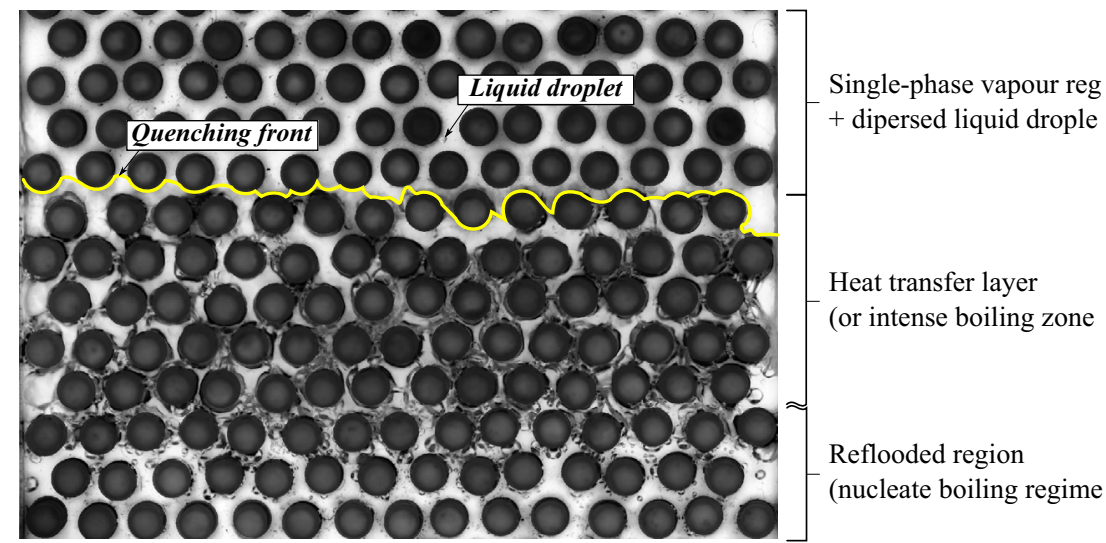

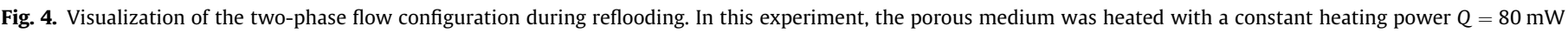
and the liquid injected at a velocity $v_{1}=3.6 \mathrm{~mm} / \mathrm{s}$.

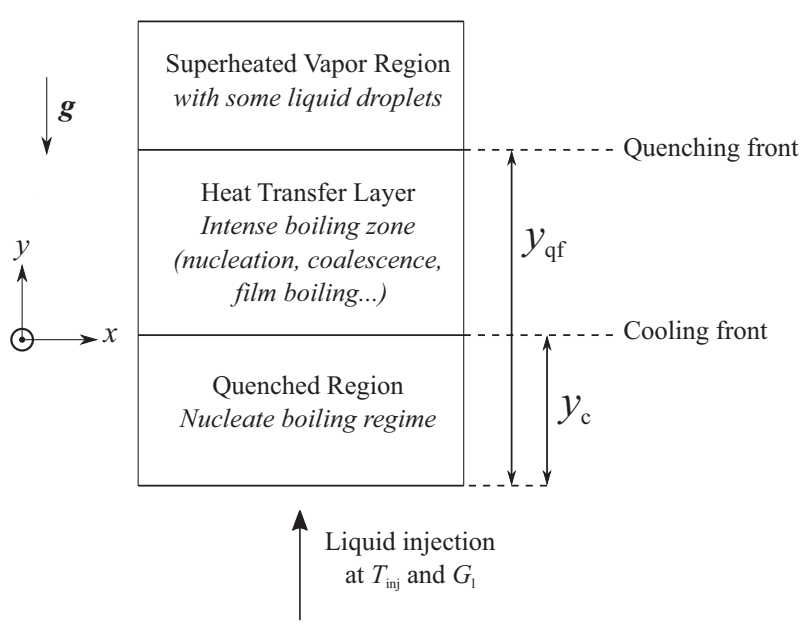

Fig. 5. Sketch of the three distinct regions observed during reflooding, with the definitions of the quenching and cooling fronts.
Such a two-phase flow configuration, sketched in Fig. 5, leads us to define a quenching front separating the two first zones (it is highlighted as a clear line in Fig. 4 cooling front separating the two last ones, that is difficult to detect precisely from visualizations. Instantaneous temperature distribution at the test section scale confirms the relevance of such a description, see Fig. 6. It is noticeable that despite the high permeability of the porous medium, the thermal gradients in the initial temperature profile (Fig. 3)) and the higher permeability at the lateral sides of the cylinder bundle, macroscopic behavior during a reflooding experiment turns out to be very close to a one-dimensional configuration with flat quenching and cooling fronts and very low thermal gradients in the $x$-direction. Consequently, quantitative information about the two fronts displacements can be obtained by focusing on the temperature evolution recorded for each heating element.

Fig. 7 displays a typical temperature $v s$ time signal obtained for a single central heating cylinder. Once reflooding starts, a significant temperature decrease is observed. The local thermal nonequilibrium between the vapor phase and the superheated solid is not the only reason for the solid element temperature decrease downstream of the quenching front. This precursory cooling is 


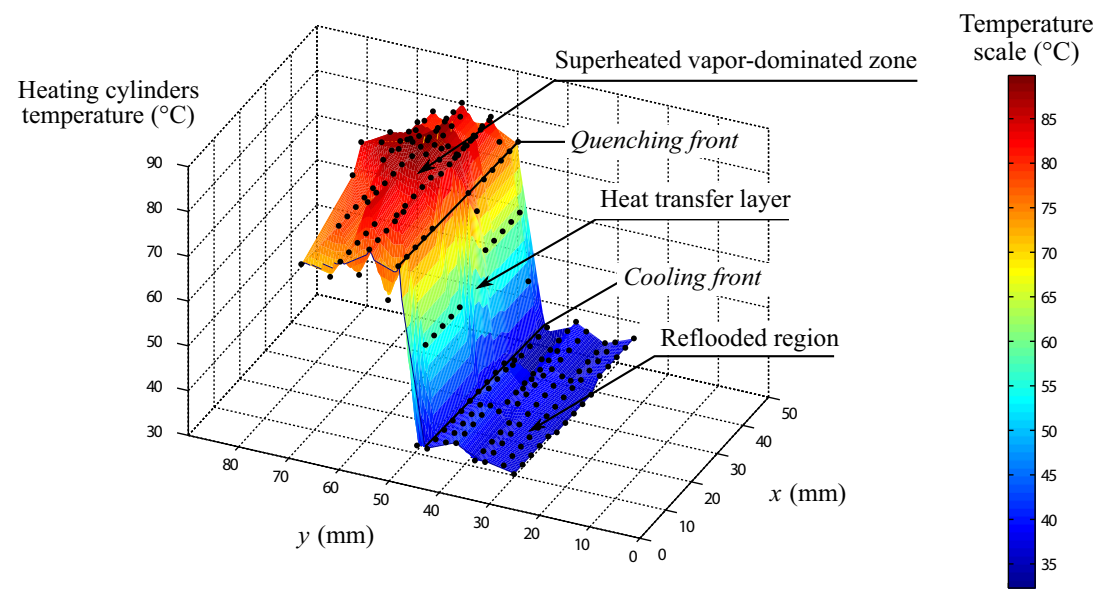

Fig. 6. Instantaneous temperature spatial distribution during reflooding, at a time corresponding to the two-phase flow distribution shown in Fig. 4.

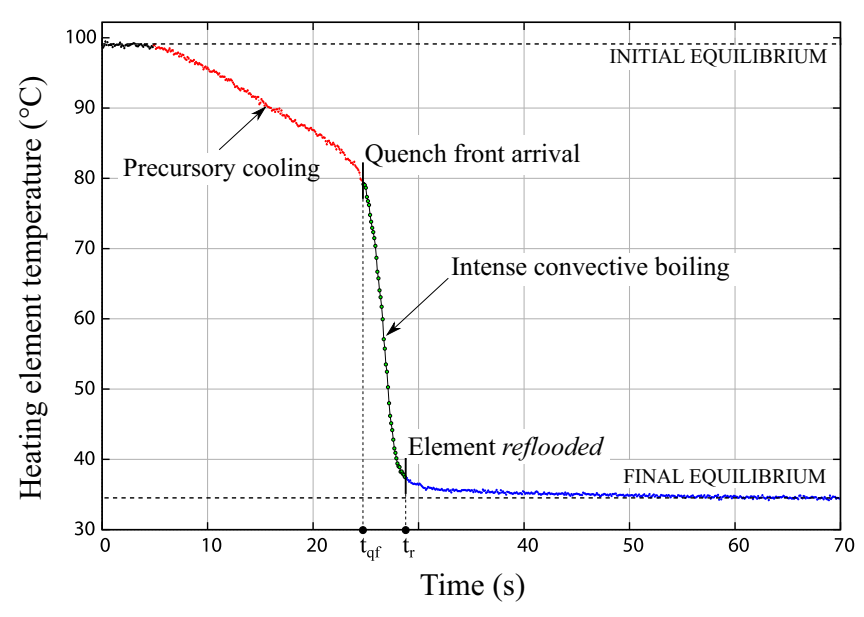

Fig. 7. Temperature evolution of a heating element during reflooding.

partly due to the forced convection associated with the vapor flow generated in the zone upstream from the quenching front, but also to heat conduction through the ceramic walls and, based on the visualizations, to sputtering of liquid drops from the quenching front. At a time noted $t_{\mathrm{qf}}\left(t_{\mathrm{qf}}=24.8 \mathrm{~s}\right.$ in Fig. 7), the heat flux extracted from the heating element increases abruptly. Eventually, the cylinder is considered to be reflooded - or cooled down - at $t_{c}$, when a permanent nucleate boiling regime is reached around it (note that a reflooded cylinder still produces vapor because the heat flux supplied to it is maintained constant during the experiment at a sufficiently high level to cause boiling).

\subsection{Quenching and cooling fronts detection}

Relating the arrival of the quenching front at the $y$-location of the considered heating element to the temperature drop observed at $t_{\mathrm{qf}}$ is a priori not straightforward. Heat diffusion through the walls and thermal inertia of the cylinders might induce a delay between the actual position of the two-phase front $y_{\mathrm{qf}}$ and the position obtained from thermal measurements $y_{\mathrm{qf}}^{\mathrm{th}}$ (deduced from the time $t_{\mathrm{qf}}$ associated with the discrete spatial $y$-location of each cylinder). Indeed, the response time of a RTD probe is approximately $0.4 \mathrm{~s}$, which is not negligible with respect to the cooling duration of a heating element $\left(t_{\mathrm{qf}}-t_{\mathrm{c}}=4 \mathrm{~s}\right.$ in this example).

The position of the quenching front $y_{\mathrm{qf}}$ can be obtained unambiguously by processing the image sequence given by the high- speed camera. After detection of the cylinders, a mask is created in order to isolate the pore space. A background is then subtracted from each image of the sequence and a canny filter is used to enhance edges (i.e. liquid-vapor interfaces in the present case). Binary images are finally generated, from which an average quenching front $y$-location can be obtained, see Fig. 8(a). In Fig. 8 (b), the temporal evolution of $y_{\mathrm{qf}}$ obtained through image processing (gray dots) is compared with that of the position $y_{\mathrm{qf}}^{\text {th }}$ derived from thermal measurements (filled black squares). The match between these two plots shows that the break in slope observed at $t_{\mathrm{qf}}$ in Fig. 7 truly corresponds to the arrival of the quenching front.

With regard to the cooling front, its location is obtained from thermal measurements only, $y_{\mathrm{c}}^{\text {th }}$ being deduced from the time $t_{\mathrm{c}}$ associated with the discrete spatial $y$-location of each cylinder.

Finally, temperature measurements can be used with confidence to track the spatial evolution of the quenching and cooling fronts locations, by determining the characteristic times $t_{\mathrm{qf}}$ and $t_{\mathrm{c}}$ for each of the heated cylinders.

\subsection{Parametric study of the quenching and cooling fronts velocities}

As discussed above, tracking the locations of both the cooling and quenching fronts is made possible by the analysis of the temperature evolution of heating elements. As shown in Fig. 8(b), $y_{\mathrm{qf}}$ increases linearly with time as soon as the quenching front has travelled over the vertical extent of a couple of rows of heating elements. A similar observation can be made for the evolution of the cooling front location $y_{c}$. Therefore, obtaining the constant quenching and cooling front velocities $v_{\mathrm{qf}}$ and $v_{\mathrm{c}}$ is straightforward and we now discuss their evolution with the experimental control parameters.

First, these two fronts velocities are plotted in Fig. 9(a) as a function of the heating power $Q$ applied to each heating element, for a constant liquid injection velocity $v_{1}=5.47 \mathrm{~mm} / \mathrm{s}$. Increasing the heating power $Q$ results in larger amount of energy to be extracted by the two-phase quenching zone, which in turn induces a decrease in the fronts velocities, as expected. The very important decrease observed in Fig. 9(a) suggests that it may be possible to reach a stationary regime for which the fronts would remain stationary. However, for the experiment performed with $Q=160 \mathrm{~mW}$, the initial temperatures in the cylinders reach $\approx 200^{\circ} \mathrm{C}$. Heating up further would threaten the integrity of the epoxy resins used to seal the RTD probes into the Macor ${ }^{\mathrm{TM}}$ plate (see Fig. 2(b)). Therefore, it was not possible to study higher power levels. 


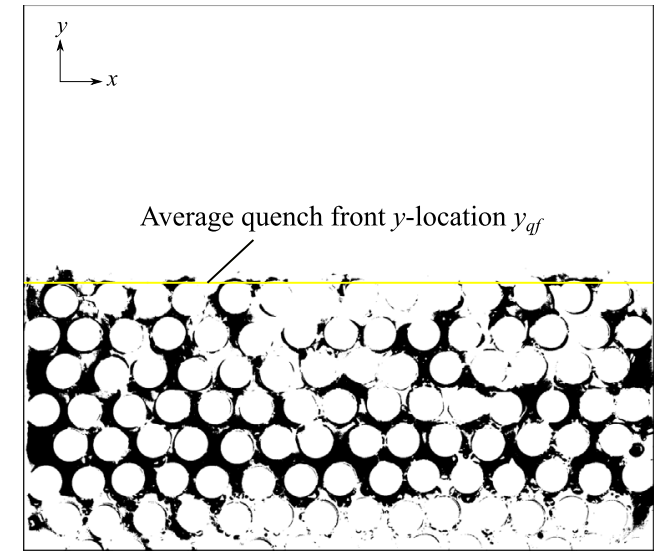

(a)

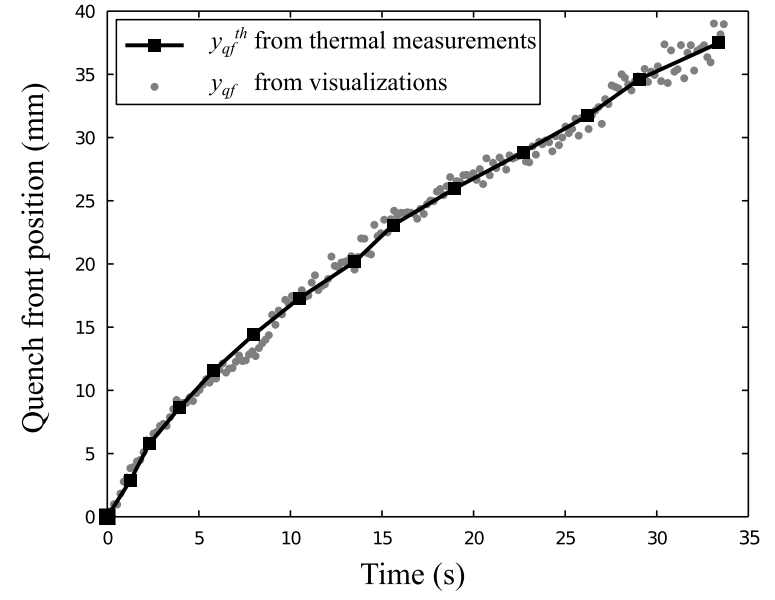

(b)

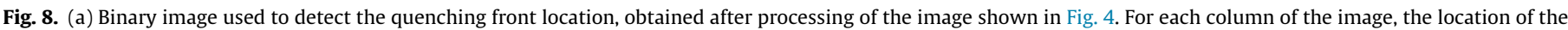

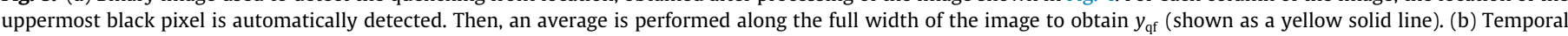

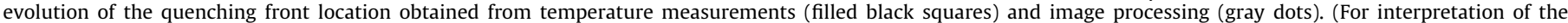
references to color in this figure legend, the reader is referred to the web version of this article.)

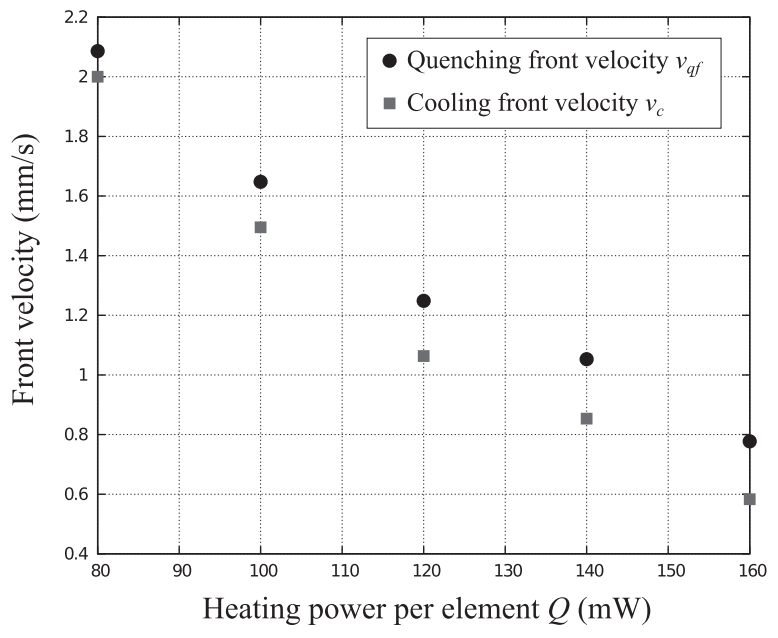

(a)

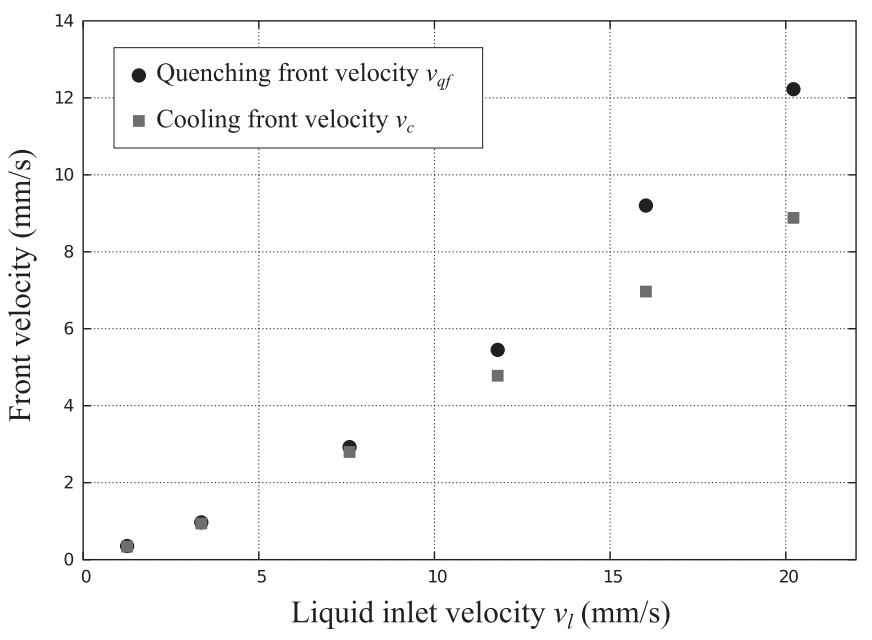

(b)

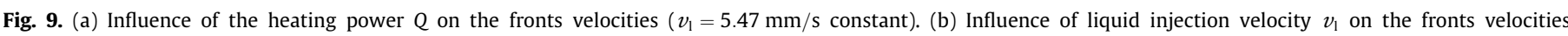
$(Q=80 \mathrm{~mW})$

Second, the fronts velocities are plotted as a function of the liquid injection velocity $v_{1}$ for a fixed heating power $Q=80 \mathrm{~mW}$, see Fig. 9(b). As expected, increasing the liquid inlet velocity causes the fronts velocities to increase as well. For injection velocity inferior to $5 \mathrm{~mm} / \mathrm{s}$, the fronts velocities are similar. However, for larger $v_{1}$, the quenching front velocity is larger and the higher $v_{l}$, the more important the difference between $v_{\mathrm{qf}}$ and $v_{\mathrm{c}}$ is. These trends are similar to those observed on 3D column packed beds such as the PRELUDE facility which consists in a $174 \mathrm{~mm}$ internal diameter cylinder filled with $200 \mathrm{~mm}$ high packed bed of steel balls heated up with induction, reflooded with bottom injection of water at ambient temperature [37].

Fig. 10 shows the evolution of the heat transfer layer vertical extent $L_{\mathrm{htl}}$ during a reflooding experiment, for the different injection velocities investigated. $L_{\mathrm{htl}}$ is measured thanks to the thermal measurements, as explained in Section 3.2, and is defined as $L_{\mathrm{htl}}=y_{\mathrm{qf}}^{\mathrm{th}}-y_{\mathrm{c}}^{\mathrm{th}}$. On each single curve, three distinct periods can be observed. The first period, during which the size of the heat transfer layer rapidly increases, corresponds to the ingress of the quenching front into the superheated test section. Once the first bottom elements of the heated part of the test section are cooled down and have reached a steady-state nucleate boiling regime, a cooling front propagates as well within the bank of cylinders, which induces the first change in slope observed on each curve. Then, both a cooling and a quenching front can be detected in the heated part of the test section, as explained above. For small liquid injection velocities ( $v_{1}=1.25$ and $3.36 \mathrm{~mm} / \mathrm{s}$ ), the extent of the heat transfer layer does not vary much with time as $v_{\mathrm{qf}}$ and $v_{\mathrm{c}}$ are very close to each other (see Fig. 9(b)), while it significantly increases as the two fronts propagates into the porous medium, for more important flow rates (for which $v_{\mathrm{qf}}>v_{\mathrm{c}}$ ). Finally, the size of the heat transfer layer diminishes once the quenching front has reached the upper limit of the heated part of the test section, until the cooling front reaches this limit as well. 


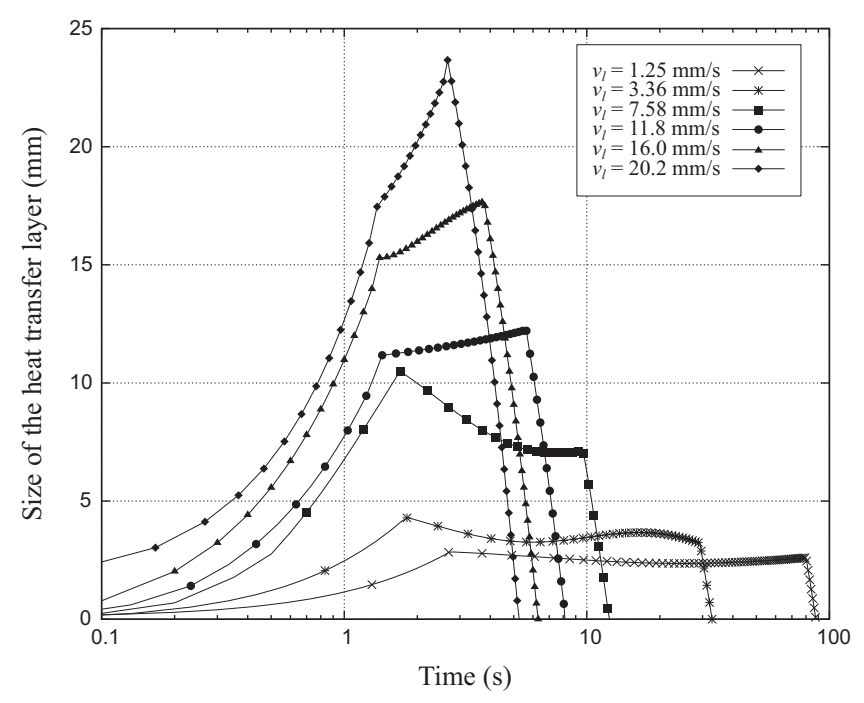

Fig. 10. Vertical extent, $L_{\mathrm{htl}}$, of the heat transfer layer as a function of time, for different fluid injection velocities $v_{1}$.

\section{Conclusion and perspectives}

The experimental setup described in this article has been developed to study reflooding with internal boiling of a heating model porous medium with mm-scale pores. The main objective is to provide precise data both at the pore and macroscopic scales, with a perspective to better understand two-phase flows in porous media with intense liquid-vapor phase change. The main element of the apparatus is a slightly disordered bundle of cylinders placed between two plates, thus forming a nearly two-dimensional particle bed. Each constitutive element is a cylindrical RTD, used both as a temperature probe and a heating element. An interactive electronic device allows real-time control of the heating power transferred to each cylinder.

Temperature evolution of the heating cylinders, together with direct visualization, enabled to identify three distinct macroscopic regions and the heat transfer processes involved. First, in the superheated vapor-dominated zone with dispersed small liquid drops, the solid matrix is cooled down by vapor forced convection, conduction through the walls and sputtering of fluid droplets from the quenching front. Second, upstream of the quenching front, the major amount of heat is extracted in a so-called heat transfer layer. In this intense boiling region, the strong vapor bubbles confinement furthers coalescence, leading to the formation of vapor slugs, which is reminiscent of microscopic boiling phenomenology. Finally, in the thermally established reflooded zone, classical convective nucleate boiling with isolated nucleation sites is observed.

Thermal measurements also enabled to measure the quenching and cooling fronts velocities for different heating powers and injection flow rates. These results from thermal measurements and direct visualizations are similar to those inferred from thermocouple data in 3D particle beds, as far as the temperature evolution at a given location within the bed is concerned or, e.g., regarding the quenching front velocity evolution with injection velocity $[37,14,15]$. That reinforces the proposed idea that the observations made on the macroscopic behavior and the reflooding dynamics in this model porous medium are representative of the physics of two-phase flows in 3D debris beds with internal boiling. The experimental setup, as well as the already obtained results, may therefore be very useful to develop more accurate pore-scale or macro-scale models and hence improve nuclear safety analysis or any other application in which intense boiling in porous media plays a major role.
In this paper, reflooding experiments were performed on a uniformly heated bank of cylinders. However, since all RTDs can be controlled individually, this setup can be used to study the influence of heterogeneous heating and the impact of a timedependent heating power $Q$, situations that one may encounter in practice, for instance in the context of nuclear reactor severe accidents. This will be the subject of future studies. Furthermore, image processing techniques are currently being developed to estimate the local void fraction field from the high speed visualizations, which would provide the necessary data for subsequent quantitative modeling analysis.

\section{Acknowledgments}

Authors are particularly grateful to Ruddy Soeparno who contributed to the technical design and realization of the experimental setup and to Hervé Ayroles who built the electronic modules controlling the RTDs. Thanks also go to Electricité de France (EDF) for funding this research project.

\section{References}

[1] V. Dhir, I. Catton, Dryout heat fluxes for inductively heated particulate beds, J. Heat Transfer 99 (2) (1977) 250-256.

[2] H. Bau, K.E. Torrance, Boiling in low-permeability porous materials, Int. J. Heat Mass Transfer 25 (1982) 45-55.

[3] K. Udell, Heat transfer in porous media heated from above with evaporation, condensation, and capillary effects, J. Heat Transfer 105 (3) (1983) 485-492.

[4] A. Reed, E. Bergeron, K. Boldt, T. Schmidt, Coolability of UO 2 debris beds in pressurized water pools: DCC-1 and DCC-2 experiment results, Nucl. Eng. Des. 97 (1) (1986) 81-88.

[5] A. Stubos, J.-M. Buchlin, Vapour channels in boiling, unconstricted particle beds - effect on the dryout heat flux, Int. J. Multiphase Flow 20 (1) (1994) 131152.

[6] L. Barleon, H. Werle, Dependence of Dryout Heat Flux on Particle Diameter for Volume-and Bottom-Heated Debris Beds, Kernforschungszentrum Karlesruhe, 1981.

[7] V. Tung, V. Dhir, D. Squarer, Quenching by top flooding of a heat generating particulate bed with gas injection at the bottom, in: The Sixth Meeting on Debris Coolability, November 7-9, 1984, Los Angeles, California, Report EPRI NP-4455, Palo Alto, California, March 1986.

[8] T. Ginsberg, J. Klein, J. Klages, Y. Sanborn, C. Schwarz, J. Chen, L. Wei Experimental and analytical investigation of quenching of superheated debris beds under top-reflood conditions. Final report, Tech. rep., Brookhaven National Lab., Upton, NY (USA) (1986).

[9] K. Hu, T. Theofanous, On the measurement and mechanism of dryout in volumetrically heated coarse particle beds, Int. J. Multiphase Flow 17 (4) (1991) 519-532.

[10] N. Tutu, T. Ginsberg, J. Klein, J. Klages, C. Schwarz, Debris Bed Quenching Under Bottom Flood Conditions, Brookhaven National Laboratory, Upton, New York, 1984. Technical Report.

[11] P. Schäfer, M. Groll, R. Kulenovic, Basic investigations on debris cooling, Nucl. Eng. Des. 236 (19) (2006) 2104-2116.

[12] I. Lindholm, S. Holmström, J. Miettinen, V. Lestinen, J. Hyvärinen, P. Pankakoski, H. Sjövall, Dryout heat flux experiments with deep heterogeneous particle bed, Nucl. Eng. Des. 236 (19) (2006) 2060-2074.

[13] K. Atkhen, G. Berthoud, SILFIDE experiment: coolability in a volumetrically heated debris bed, Nucl. Eng. Des. 236 (19-21) (2006) 2126-2134.

[14] A. Bachrata, F. Fichot, G. Repetto, M. Quintard, J. Fleurot, Quench front progression in a superheated porous medium: experimental analysis and model development, J. Energy Power Eng. 7 (2013) 514-523.

[15] N. Chikhi, T. Garcin, F. Foubert, P. March, F. Fichot, First experimental results of large scale debris bed reflood tests in the pearl facility, in: 16th International Topical Meeting on Nuclear Reactor Thermal Hydraulics (NURETH 16), 2014.

[16] A. Stubos, J.-M. Buchlin, Analysis and numerical simulation of the thermohydraulic behaviour of a heat dissipating debris bed during power transients, Int. J. Heat Mass Transfer 36 (5) (1993) 1391-1401.

[17] R. Lipinski, A coolability model for postaccident nuclear reactor debris, Nucl, Technol. (United States) 65 (1) (1984) 53-66.

[18] T. Schulenberg, U. Müller, An improved model for two-phase flow through beds of coarse particles, Int. J. Multiphase Flow 13 (1) (1987) 87-97.

[19] V. Tung, V. Dhir, A hydrodynamic model for two-phase flow through porous media, Int. J. Multiphase Flow 14 (1) (1988) 47-65.

[20] K. Atkhen, G. Berthoud, Experimental and numerical investigations on debris bed coolability in a multidimensional and homogeneous configuration with volumetric heat source, Nucl. Technol. 142 (3) (2003) 270-282.

[21] M. Bürger, M. Buck, W. Schmidt, W. Widmann, Validation and application of the WABE code: investigations of constitutive laws and 2D effects on debris coolability, Nucl. Eng. Des. 236 (19) (2006) 2164-2188. 
[22] F. Fichot, F. Duval, N. Trégourès, C. Béchaud, M. Quintard, The impact of thermal non-equilibrium and large-scale 2D/3D effects on debris bed reflooding and coolability, Nucl. Eng. Des. 236 (19-21) (2006) 2144-2163.

[23] F. Duval, F. Fichot, M. Quintard, A local thermal non-equilibrium model for two-phase flows with phase-change in porous media, Int. J. Heat Mass Transfer 47 (3) (2004) 613-639.

[24] S. Whitaker, The Method of Volume Averaging, vol. 13, Springer, Netherlands, 1999.

[25] S. Whitaker, Flow in porous media II: the governing equations for immiscible, two-phase flow, Transp. Porous Media 1 (2) (1986) 105-125.

[26] Y. Davit, B. Wood, G. Debenest, M. Quintard, Correspondence between oneand two-equation models for solute transport in two-region heterogeneous porous media, Transp. Porous Media 95 (2012) 213-238, http://dx.doi.org/ 10.1007/s11242-012-0040-y.

[27] Y. Davit, M. Quintard, Handbook of Porous Media, third ed., Theoretical analysis of transport in porous media: Multi-Equation and Hybrid Models for a Generic Transport Problem with Non-Linear Source Terms, Taylor \& Francis, 2015. ch. 7.

[28] S. Liter, M. Kaviany, Pool-boiling CHF enhancement by modulated porouslayer coating: theory and experiment, Int. J. Heat Mass Transfer 44 (22) (2001) 4287-4311.

[29] V. Dhir, Boiling heat transfer, Annu. Rev. Fluid Mech. 30 (1) (1998) 365-401.

[30] V. Dhir, Mechanistic prediction of nucleate boiling heat transfer-achievable or a hopeless task?, J Heat Transfer 128 (1) (2006) 1-12.

[31] P. Kew, K. Cornwell, Correlations for the prediction of boiling heat transfer in small-diameter channels, Appl. Therm. Eng. 17 (8-10) (1997) 705-715.

[32] J. Thome, Boiling in microchannels: a review of experiment and theory, Int. J. Heat Fluid Flow 25 (2) (2004) 128-139.

[33] P. Cheng, H. Wu, Mesoscale and Microscale Phase-Change Heat Transfer, Advances in Heat Transfer, vol. 39, Elsevier, 2006, pp. 461-563.

[34] T. Ginsberg, J. Klein, C. Schwarz, J. Klages, Transient core debris bed heat removal experiments and analysis, in: International Meeting on Thermal Nuclear Reactor Safety, 1982.
[35] M. Rashid, R. Kulenovic, E. Laurien, Experimental results on the coolability of a debris bed with down comer configurations, Nucl. Eng. Des. 249 (2012) 104110.

[36] C. Wang, V. Dhir, An experimental investigation of multidimensiona quenching of a simulated core debris bed, Nucl. Eng. Des. 110 (1) (1988) 61 72.

[37] G. Repetto, T. Garcin, S. Eymery, F. Fichot, Experimental program on debris reflooding (PEARL) - results on PRELUDE facility, Nucl. Eng. Des. 264 (2013) 176-186.

[38] F. Fichot, A. Bachrata, G. Repetto, J. Fleurot, M. Quintard, Quenching of a highly superheated porous medium by injection of water, Journal of Physics: Conference Series, vol. 395, IOP Publishing, 2012, p. 012144.

[39] R. Roser, B. Thonon, P. Mercier, Experimental investigations on boiling of npentane across a horizontal tube bundle: two-phase flow and heat transfer characteristics, Int. J. Refrig. 22 (7) (1999) 536-547.

[40] L. Liao, Z.-H. Liu, Enhanced boiling heat transfer of the compact staggered tube bundles under sub-atmospheric pressures, Heat Transfer Eng. 28 (5) (2007) 444-450.

41] L. Aprin, P. Mercier, L. Tadrist, Local heat transfer analysis for boiling of hydrocarbons in complex geometries: a new approach for heat transfer prediction in staggered tube bundle, Int. J. Heat Mass Transfer 54 (19) (2011) 4203-4219.

[42] J. Broughton, P. Kuan, D. Petti, E. Tolman, A scenario of the three mile island unit 2 accident, Nucl. Technol. 87 (1989) 34-53.

[43] R. McCardell, M. Russell, D. Akers, C. Olsen, Summary of TMI-2 core sample examinations, Nucl. Eng. Des. 118 (3) (1990) 441-449.

[44] E. Coryell, D. Akers, C. Allison, M. Carbonneau, R. Hobbins, J. Hohorst, S. Jensen S. Modro, Summary of important results and SCDAP/RELAP5 analysis for OECD LOFT experiment LP-FP-2, Technical Report NUREG/CR-6160, Washington D.C. 1994.

[45] R. Manzel, C. Walker, EPMA and SEM of fuel samples from PWR rods with an average burn-up of around $100 \mathrm{MWd} / \mathrm{kgHM}$, J. Nucl. Mater. 301 (2) (2002 $170-182$. 